\title{
TRABALHO E CIDADANIA: O PAPEL DO ESTADO BRASILEIRO NO SÉCULO XX
}

Rafael Egidio Leal e Silva ${ }^{1}$, Regiane Cristina de Souza ${ }^{2}$

${ }^{1}$ Universidade Estadual de Maringá, Mestrando do Programa de Pós Graduação em Psicologia. Docente da Faculdade de Astorga (Faast). E-mail: lealesilva@gmail.com. ${ }^{2}$ Universidade Estadual de Maringá, Mestranda do Programa de Pós Graduação em Psicologia. Docente do CESUMAR-Maringá. Docente da Faculdade de Astorga (Faast).

\section{RESUMO}

O objetivo deste texto é investigar o conceito de "cidadania regulada" e suas relações com a implantação do trabalho urbano e livre no Brasil, a partir dos anos $30 \mathrm{com}$ o governo de Getúlio Vargas, e como tal cidadania ajudou a moldar o Estado Desenvolvimentista que, a partir dos anos 50, passou a implantar o capitalismo e, até mesmo, a moldar o trabalhador brasileiro. Desta forma, devemos entender que a escravidão deixou marcas profundas na formação da sociedade brasileira: o trabalho foi pautado a partir de suas heranças rurais, ou seja, baseado na hierarquia do senhor e do escravo, e a cidadania que também foi vista como a forma hierárquica que o individuo se encaixa na sociedade. Para então discutirmos o conceito e até mesmo os rumos do trabalho no Brasil, devemos compreender a formação histórica e social do trabalhador e do conceito de trabalho, que nossa sociabilidade construiu.

Palavras-chave. Trabalho. Cidadania. Estado brasileiro.

\section{WORK AND CITIZENSHIP: THE ROLE OF THE BRAZILIAN STATE IN THE TWENTIETH CENTURY.}

\section{ABSTRACT}

The purpose of this paper is to investigate the concept of "Regulated citizenship" and relations with the implementation of urban and free labor in Brazil, from the government of Getulio Vargas in the 1930s, and how it contributed to form the Developmental State that from the 50's, began to promote the capitalism and even form the Brazilian worker. We must understand that slavery has left deep scars on the formation of Brazilian society: the work was guided from its rural origins, based on the hierarchy of master and slave, citizenship and who was also regarded as the hierarchical form that the person fits into society. To discuss the concept and direction of work in Brazil, we must understand the social history of the worker and the concept of work that built our sociability.

Keywords. Work. Citizenship. Brazilian state. 


\section{INTRODUÇÃO E JUSTIFICATIVA.}

Os rumos da organização - e administração - do trabalho no século $X X$ atenderam as necessidades sócio-históricas e os contextos do capitalismo, da necessidade de produção e acumulação do capital. Desta forma, não podemos falar de fases da administração do trabalho, pois o que aconteceu foi a adoção e adaptação de sistemas criados com o intuito de se racionalizar a produção e a otimização dos recursos (materiais e humanos) em determinados contextos específicos, como é claro no taylorismo e no toyotismo. Mas e o Brasil? Como então se organizou o trabalho no século $X X$ em nossas terras? A lógica de organização teria sido a mesma dos Estados Unidos e Japão, ou da Europa? Seguramente que não, e justamente por dois aspectos fundamentais: primeiramente, a escravidão longa, penitente e traumática que aniquilou, durante três longos séculos, a formação de um conceito de trabalho e de um trabalhador. Em segundo lugar, o papel do Estado Brasileiro, que sempre mediou, politicamente, a economia do país. Se o Estado Moderno foi criado para ser o suporte político e institucional do capitalismo, aqui o Estado era comprometido com as oligarquias rurais (comprometidas com a escravidão) que não permitiam a industrialização e a urbanização do país. No entanto, mesmo depois dos anos 30 do século passado, quando houve um esforço maciço por parte de Getúlio Vargas (1882-1954), as oligarquias não deixaram de existir, fazendo, assim, que os rumos do capitalismo no Brasil fossem esquadrinhados e calculados pela agenda política.

Tal discussão justifica-se por questionar e lançar o debate sobre conceitos essenciais para a discussão da sociedade brasileira, sua origem e seus rumos. A discussão histórica permite localizar como tais conceitos estão atrelados ao processo histórico e social e como, deste modo, a cidadania e o trabalho possuem implicações peculiares no Brasil.

\section{OBJETIVO}

Nosso objetivo neste artigo é investigar como tais "labirintos" da política brasileira estabeleceram $\mathrm{o}$ conceito de trabalhador $\mathrm{e}$ cidadão, a partir dos anos 30 , e que chegaram até o contexto do trabalho nos anos 80 e 90 . Discutiremos como a escravidão nas terras brasileiras influiu, indelevelmente, no conceito de trabalho e cidadania, além do papel de Vargas na formação da identidade do trabalhador e nos rumos do desenvolvimento econômico nos anos seguintes e como tais políticas influíram na organização do trabalho no Brasil.

\section{METODOLOGIA}

Pesquisa de caráter bibliográfico. O texto, ora apresentado, é resultado da investigação em textos das áreas de Ciência Política, Sociologia e do Pensamento Social Brasileiro, que tenham como tema a problematização da formação histórica e social do trabalhador e do cidadão no Brasil, de forma a podermos questionar a relação de tais conceitos e seu papel na sociedade brasileira.

\section{RESULTADOS E DISCUSSÃO}

Conforme dissemos, a escravidão deixou marcas profundas no conceito de trabalho $e$ trabalhador no Brasil. A escravidão, implantada nessas terras, não teve apenas o objetivo de exploração econômica, mas de apropriação de outros povos, como penitência religiosa da expansão pela fé ultramarina portuguesa. Podemos dizer, assim como Oliveira, que a escravidão trouxe "as cores fortes da violência sexual como apropriação do corpo e anulação do outro, na proibição dos cultos africanos como proibição da fala, no rigor dos castigos como proibição da reivindicação" (OLIVEIRA, 1999, p. 
59). Se o trabalho é forma de criação de relações humanas, na escravidão tais relações estão totalmente transfiguradas e fortemente violentadas. $O$ trabalho escravo não é um direito ou um dever: é uma propriedade que aniquila a humanidade do escravo, transforma em divino o senhor, proprietário daquelas vidas.

É interessante notarmos que a escravidão no Brasil Colônia significou muito mais que um padrão de produção: significou a elaboração de uma verdadeira cultura na sociedade brasileira. A vida do engenho foi transposta para a sociedade urbana, ao contrário de países como França e Inglaterra que, na formação de sua sociedade moderna, industrial e capitalista, os mundos urbanos e rurais encontravam-se em oposição. No Brasil, a cidade passou a reproduzir o campo, inclusive com a concepção que o trabalho era um castigo destinado a povos não cristianizados da África. A partir das teses de Sérgio Buarque de Holanda, Sallum Jr. comenta:

[...] na ausência de uma
burguesia urbana
independente, as principais
ocupações citadinas acabam
sendo preenchidas por donos
de engenhos, lavradores, ou
seus descendentes, os quais
acabaram por transportar para
as cidades a mentalidade, os
preconceitos e, na medida do
possível, o estilo de vida
originário dos domínios rurais.
A mentalidade de casa-grande
teria invadido, assim, as
cidades e conquistado todas as
profissões, sem excluir as mais
humildes. (SALLUM JR., 2004,
p. 246)

Tal processo, herdado de séculos de Colônia, teve suas consequencias presentes em nossa sociedade. Esta herança rural teria gerado, segundo Sérgio Buarque de Holanda, em seu clássico Raízes do Brasil, o "homem cordial", que, significa não a cordialidade do trato, mas 0 agir de forma sentimental, como se estivesse no âmbito da família, a "organização de defesa ante a sociedade" (HOLANDA, 1995, p. 147) que, para o brasileiro, "a vida em sociedade é, de certo modo, uma verdadeira libertação do pavor que ele sente em viver consigo mesmo" (HOLANDA, 1995, p. 147). Assim, o homem cordial, o indivíduo brasileiro, para viver em sociedade, no espaço público, precisa transformá-lo em espaço privado, como se fosse extensão de sua casa ou de sua família. Ao criar os laços emotivos, abandona a racionalidade e os direitos. Tal formação foi fundamental na constituição da cidadania no Brasil.

A cidadania inglesa, na conhecida análise de E. P. Thompson, foi construída em cima de profundo sentimento de liberdade; a francesa assentou nos princípios da liberdade, da igualdade, da fraternidade; a norte-americana emergiu das comunidades livres da Nova Inglaterra. A brasileira foi implantada a porrete. O cidadão brasileiro é 0 individuo que [...] tem o gênio quebrado a paulada, é o indivíduo dobrado, amansado, moldado, enquadrado, ajustado a seu lugar. $O$ bom cidadão que se sente livre e igual, é o que se encaixa na hierarquia que lhe é prescrita. (CARVALHO, 2005, p. 307).

Desta forma, a cidadania no Brasil teve um caminho completamente diferente do de outros países. Onde podemos, assim, localizar essa diferença histórica? Com certeza, os séculos de escravidão explicam muito, pois a categoria trabalho, fundamental para a formação do cidadão livre e igual da modernidade, foi completamente enviesada em nossas terras. $\mathrm{O}$ fim da escravidão gerou esse impasse: como transformar essa visão de trabalho? A imigração foi uma forma, mas mesmo o imigrante que aqui chegara, que conceito de trabalho encontrou?

Produzir, portanto, identidade social e política para 0 trabalhador era um esforço muito grande. Em primeiro 
lugar, porque tratava-se de afirmar a dignidade do próprio ato de trabalhar e da figura do trabalhador em distinção à figura do escravo. Não se possuía no Brasil um passado de tradições que se pudesse recorrer ou que esse pudesse acionar em auxílio à construção deste perfil de trabalhador. Tratava-se, ao contrário, de superar o passado escravista, em nome do futuro de um novo trabalhador. Só que este sujeito sem passado, também não possuía contornos nítidos no presente. Como em outras experiências históricas, os trabalhadores do Brasil de fins do século XIX não são um todo homogêneo. Eles se diferenciam em cor, sexo, nacionalidade (a imigração cresce até os anos 20), e se autodefinem como artistas, operários, artesãosassalariados, funcionários, etc. (GOMES, 1991, p. 72).

Foi com a Revolução de 1930 que houve uma mudança acerca do desenvolvimento econômico do Brasil. Assim, o rompimento com o passado oligárquico e rural foi levado à frente pelos novos governantes, com a bandeira do desenvolvimento capitalista, industrial e urbano, levado à frente pelo Estado fortalecido e centralizador. Se a era varguista pode ser considerada a era do trabalhismo, quem é então esse trabalhador dos anos 30 ? Como se formou sua identidade? Se o "trabalhador" não foi formado historicamente, como se deu esse processo? O novo governo, centralizador (a ponto de ter sua face autoritária, de 1937 a 1945), buscou, pela via das leis e da cidadania a formação da consciência do trabalho. Vejamos nesta citação de Santos:

Sugiro que o conceito-chave que permite entender a política econômico-social pós-30, assim como fazer a passagem da esfera da acumulação para a esfera da eqüidade é o conceito de cidadania, implícito na prática política do governo revolucionário, e que tal conceito poderia ser descrito como de cidadania regulada. Por cidadania regulada entendo o conceito de cidadania cujas raízes encontram-se, não em um código de valores políticos, mas em um sistema de estratificação ocupacional, e que, ademais, tal sistema de estratificação ocupacional é definido por norma legal. Em outras palavras, são cidadão todos aqueles membros da comunidade que se encontram localizados em qualquer uma das ocupações reconhecidas em lei. A extensão da cidadania se faz, pois, via regulamentação de novas profissões e/ou ocupações, em primeiro lugar, e mediante a ampliação do escopo dos direitos associados a estas profissões, antes que por expansão dos valores inerentes ao conceito de membro da comunidade. A cidadania está embutida na profissão e os direitos do cidadão restringemse aos direitos do lugar que ocupa no processo produtivo, tal como reconhecido em lei. (SANTOS, 1987, p. 68).

Podemos, assim, perceber que a luta pela formalidade e mesmo pela legitimidade passa a ser buscada sempre no campo jurídico: há a necessidade da lei, da sentença, e não do acordo ou do contrato. A cidadania tem o caminho "de cima para baixo" reforçado. O trabalhador funde-se com o cidadão, ou seja, seus direitos só podem ser peticionados se fizer parte da parcela com lugar jurídico na sociedade, ou seja, se houver uma lei que reconheça e defina sua profissão. Se assim o trabalhador ganhava uma identidade (esquecido o passado de escravo) temos aqui, novamente, a confusão da economia com a política, e com o jurídico. Claro que para as classes dominantes (oligárquicas inclusive) esta situação foi bastante favorável. Mesmo no ambiente urbano ficava possível distinguir, rapidamente, o legítimo do 
não-regulado, e destes, do marginal. Institui-se o símbolo da cidadania regulada:

Paralelamente, instituía-se, em 1932, a carteira de trabalho, que era a evidência jurídica fundamental para o gozo de todos os direitos trabalhistas, e nela fixava-se a profissão do trabalhador. Ao mesmo tempo, produzia-se abundante legislação regulando categoria após categoria econômica, na área urbana, evidentemente, sem o que seria impossível a implementação das leis. [...].

A regulamentação das profissões, a carteira profissional e 0 sindicato público definem, assim, os três parâmetros no interior dos quais passa a definir-se a cidadania. Os direitos dos cidadãos são decorrência dos direitos das profissões e as profissões só existem via regulamentação estatal. 0 instrumento jurídico comprovante do contrato entre - estado e a cidadania regulada é a carteira profissional que se torna, em realidade, mais do que uma evidência trabalhista, uma certidão de nascimento cívico. (SANTOS, 1987, p. 69).

Podemos notar que a grande diferença da organização do trabalho no Brasil é que ela é feita, obrigatoriamente, discutindo o papel do Estado. A carteira de trabalho não é um símbolo da identidade do trabalhador, mas o atestado de cidadania do sujeito. Mais ainda, seu atestado de normalidade, no sentido das normas jurídicas que o regem e protegem. Tanto o taylorismo, fordismo e toyotismo ocorreram dentro das fábricas, e em muito pouco podemos observar seus idealizadores falando de política ou de normas jurídicas. No entanto, seus objetivos eram bem claros: transformar, selecionando, trabalhadores adaptados à nova realidade do mercado. O regime trabalhista instaurado por Vargas tinha a mesma finalidade seletiva, mas era uma seleção que abrangia a esfera política da sociedade. Os sindicatos eram a mediação entre o trabalho e a política, entre o Estado e a economia. Outras formas de organização dos trabalhadores foram suprimidas:

"É notável e reconhecido na
literatura, que tanto as
sociedades de ajuda mútua
organizadas pelo operariado,
quanto os próprios sindicatos,
anarquistas, anarco-
sindicalistas, socialistas e,
posteriormente, comunistas,
foram anulados e
transformados pela ditadura de
Vargas nos Institutos de
Previdência e nos sindicatos
tutelados" (OLIVEIRA, 1999, p.
61 ).

Assim, o Estado centralizava tudo o que se referia ao trabalho. A identidade do trabalhador brasileiro é, em sua origem, uma identidade estatizada, definida milimetricamente por séculos de tradição jurídica que permitiu que a Justiça do Trabalho fosse tão bem definida, pairando como instância aparentemente isenta nos conflitos desta natureza. O sistema previdenciário atrela, definitivamente, o trabalhador à burocracia estatal e o deixa, em todas às fases de sua vida funcional e de aposentado, atrelado ao Estado. No entanto, para ter acesso ao sistema previdenciário, era necessário que o sujeito fosse um cidadão, devidamente regulado:

O sistema previdenciário estatal permitiu, assim, a consolidação dos laços que amarravam a um mesmo destino a oligarquia política que controlava as instituições do Ministério do Trabalho e a oligarquia sindical que controlava os organismos operários. $\mathrm{Na}$ base de tudo encontrava-se a prática da cidadania regulada, sem a qual todo o sistema de controle sindical e de distribuição de benefícios previdenciários compensatórios perderia eficácia. (SANTOS, 1987, p. 71). 
O que é interessante notarmos é que este Estado, gestado nos anos 30, serviu de base para os próximos governos que the sucedeu, até fins dos anos 80. Muito embora tenha sido questionado, modificado, o Estado brasileiro desta parte do século $X X$ foi alavancado pelo pacto desenvolvimentista, ou seja, o Estado como norteador e patrocinador do desenvolvimento do capitalismo. O capitalismo, desta forma, foi implantado de forma segura, gradual, lenta, sob a batuta da política que via nos acordos entre os setores burgueses e oligárquicos nacionais a melhor forma de conduzir a economia do país:

Mesmo industrializante, o
Estado Desenvolvimentista
brasileiro nuncar foi
representante político de uma
burguesia conquistadora, com
vocação para moldar a
totalidade da vida social aos
padrões do capitalismo
industrial e da sociedade de
classes desenvolvidar Pelo
contrário, nascido em 1930 de
uma peculiar acomodação
entre oligarquias agromercantis
e setores urbanos emergentes,
o Estado foi ajustando-se ao
crescente domínio da
burguesia industrial mas esta
nunca rompeu politicamente
com as frações "atrasadas" da
burguesia, fossem rurais
fossem urbanas, apenas
deslocou-as para posições
subalternas." (SALLUM JR.,
1996, p. 46).

Desta forma, o Estado

Desenvolvimentista era a forma que as elites tinham para acomodarem-se no poder e manter, assim, as rédeas da economia. O que fizeram os governos até os anos 80 foi manterem o pacto, ainda que de forma exacerbadamente cruel, como em 1964:

O golpe de Estado de 1964 e toda sua duração não foram senão o esforço desesperado de anular a construção política que as classes dominadas haviam realizado no Brasil, pelo menos desde os anos trinta.
Tortura, morte, exílio, cassação de direitos, tudo era como uma sinistra repetição da apropriação dos corpos e do seu silenciamento, do seu vilipendiamento, da saga gilbertiana. Sindicatos mais que tutelados passaram a administrações diretamente nomeadas pelo Ministério do Trabalho, além, é claro, da regulação administrativa dos conflitos e da fixação, igualmente por via administrativa, dos salários, seus pisos, e, por conseqüência, seus tetos, e a própria formação do mercado de força de trabalho. (OLIVEIRA, 1999, p. 64.)

\section{CONCLUSÃO}

Podemos perceber, então, que o trabalhador brasileiro foi forçosamente forjado através da cidadania regulada. Aliás, a cidadania em si foi totalmente regulada em sua configuração no século XX. Esta citação de Francisco de Oliveira faz um interessante paralelo com o Brasil Colonial e escravocrata e a ditadura militar, comprometida com aquilo que, justamente, nasceu da negação do passado colonial brasileiro. Desta forma, podemos perceber que a escravidão e o processo de colonização no Brasil deixaram raízes profundas na configuração de nossa sociedade, o que se reflete na visão de trabalhador e do cidadão.

No entanto, se tal configuração ocorreu a partir de nossa "herança rural", percebemos que, com a modernização da sociedade, tais amarras ao passado não foram completamente superadas, pelo menos em relação ao Estado Desenvolvimentista. Talvez seria, então, o caso de refletirmos: em nossos tempos de pósmodernidade e de crise do Estado, a cidadania continua regulada? E qual seria seu "símbolo"?

\section{REFERÊNCIAS}

CARVALHO, J. Pontos e bordados: escritos de história e política. Belo Horizonte: UFMG, 1998. 
GOMES, A. de C. República, trabalho e cidadania. In: BOSCHI, R. R. (Org.). Corporativismo e desigualdade: a construção do espaço público no Brasil. Rio de Janeiro: Rio Fundo Ed.; IUPERJ, 1991.

HOLANDA, S. Raízes do Brasil. 26.ed. São Paulo: Companhia das Letras, 1995.

OLIVEIRA, F. Privatização do público, destituição da fala e anulação da política: o totalitarismo neoliberal. In: OLIVEIRA, F.; PAOLI, M. C. (orgs.). Os sentidos da democracia: políticas de dissenso e hegemonia global. Petrópolis - RJ: Editora Vozes; Brasília: NEDIC, 1999.

SALLUM JR., B. Labirintos: dos generais à Nova República. São Paulo: Hucitec, 1996.

SALLUM JR., B. Raízes do Brasil. In: MOTA, L. Introdução ao Brasil: um banquete no Trópico. 4.ed. São Paulo: Senac, 2004.

SANTOS, W. G. Cidadania e Justiça: A Política Social na Ordem Brasileira. 2.ed. Rio de Janeiro: Editora Campus, 1987. 